\title{
Aggressive Angiomyolipomas: the Clandestine Epithelioid Variant
}

\author{
Anton Maré $^{\mathrm{a}}$ Shehan Wickramasinghe ${ }^{\mathrm{b}} \quad$ Victor Ilie $^{\mathrm{a}} \quad$ Maurice Mulcahy $^{\mathrm{a}}$ \\ aDepartment of Urology; and 'Department of General Surgery, The Canberra Hospital, ACT, Australia
}

\section{Key Words}

Angiomyolipoma • Computed tomography •

Renal cell carcinoma

\begin{abstract}
Epithelioid angiomyolipoma is a rare mesenchymal derived neoplasm of the kidney. Thought to be a variant of classical angiomyolipoma, a benign tumour, its malignant potential has been highlighted by case reports of loco-regional and distant metastasis. Given the potentially adverse clinical course associated with epithelioid angiomyolipoma compared to classical angiomyolipoma, the distinction and comprehensive histological characterisation of this rare entity is essential.

Copyright $\odot 2015$ S. Karger AG, Basel
\end{abstract}

\section{Introduction}

Epithelioid angiomyolipoma (EAML) is a rare mesenchymal derived neoplasm of the kidney [1]. Thought to be a variant of classical angiomyolipoma, a benign tumor, its malignant potential has been highlighted by case reports of loco-regional and distant metastasis [2-4]. Given the potentially adverse clinical course associated with EAML compared to classical angiomyolipoma, the distinction and comprehensive histological characterisation of this rare entity is essential.

\section{KARGER}

Fax +4161306 1234

E-Mail karger@karger.ch

www.karger.com
(C) 2015 S. Karger AG, Basel

1015-9770/14/0091-0054\$38.00/0

Accessible online at:

www.karger.com/cur

\section{Case Report}

We illustrate the diagnostic and management issues associated with this pathology in the case of a 55 year old female who presented via the emergency department with left lower quadrant abdominal discomfort and a palpable mass. Investigations revealed microcytic anemia and, on CT, a significant mass originating from the lower pole of the left kidney. This was diagnosed initially as a large renal cell carcinoma (RCC) without evidence of distant metastasis (fig. 1).

The tumor was removed via an open left radical nephrectomy. The lower pole tumor had generated extensive neovascularisation and was tenting the left colic and sigmoid vessels, making dissection difficult. After complete resection, the patient had an uneventful post-operative recovery and was discharged home day four.

Histology of the resected specimen revealed an EAML measuring $17 \times 11 \times 10 \mathrm{~cm}$. Macroscopically the mass was well circumscribed, exerting a mass effect on the renal pelvis but without signs of frank invasion (fig. 2).

Microscopically the specimen had large cells with abundant eosinophilic cytoplasm and moderately pleomorphic nuclei with prominent nucleoli. There were scattered rhabdoid-like and ganglion-like cells with numerous florette-type multinucleated giant cells. Despite the cellular atypia, mitotic figures were hard to find (fig. 3). Tumor necrosis and vascular space invasion were present. The entire tumor was epithelioid with no areas of conventional angiomyolipoma. Immunohistochemistry was positive for E-cadherin, Melan-A and HMB-45.

\section{Discussion}

It is now known that EAML is a neoplasm arising from the clonal proliferation of a progenitor cell (the perivascular epithelioid cell), which can differentiate

Anton Maré

Department of Urology, The Canberra Hospital

Yamba Drive, Garran

ACT (Australia)

E-Mail anton.mare@act.gov.au 


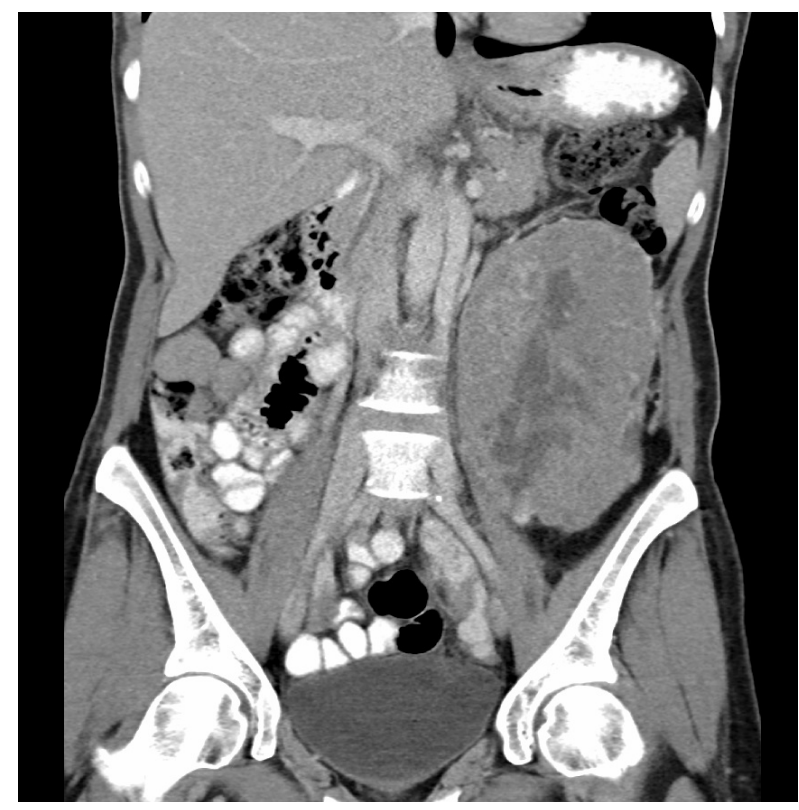

Fig. 1. CT abdomen showing a large heterogenous mass obliterating the inferior pole of the left kidney.

into muscle, adipose and epithelioid cells [5]. The clinical presentation for EAMLs is varied - most are incidental findings however haematuria, anemia, and flank pain are possible. There is an association with tuberous sclerosis complex as $50 \%$ of patients with tuberous sclerosis complex have angiomyolipomas, usually multiple and bilateral [6].

Histologically, classical angiomyolipoma contain muscle, adipose and blood vessels. EAML on the other hand is characterised by the predominance of perivascular epitheloid cells [5]. Both types stain positive for immunohistochemical markers such as HMB45, melan-A and smooth muscle actin [7]. It is difficult to diagnose malignancy in EAML as not all cases with cellular atypia are malignant [8]. Controversy exists as to when a classical angiomyolipoma should be referred to as an EAML, however it is generally agreed that if the epithelioid component comprises more than $5 \%$ of the specimen, it should be referred to as an EAML [9]. Two large multicentric retrospective studies identified 1) a large epithelioid cell component; 2) severe nuclear atypia; 3) extent of nuclear atypia; 4) mitotic count; 5) presence of atypical mitotic figures; 6) necrosis and 7) the presence of lymphovascular invasion as adverse histological features associated with malignancy, in conjunction with tumor size $>7 \mathrm{~cm}$ and renal vein invasion $[5,10]$.

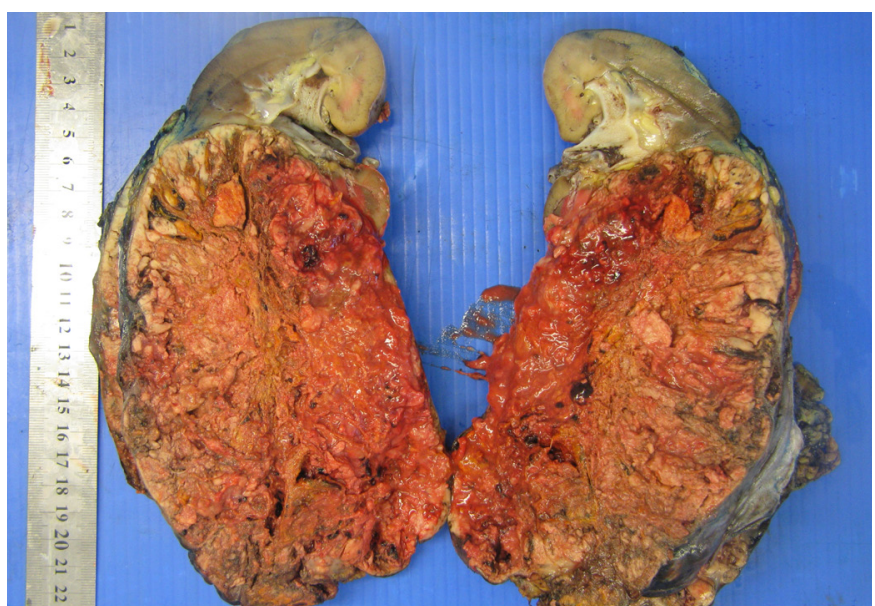

Fig. 2. Macroscopic image of the resected specimen - epithelioid angiomyolipoma.

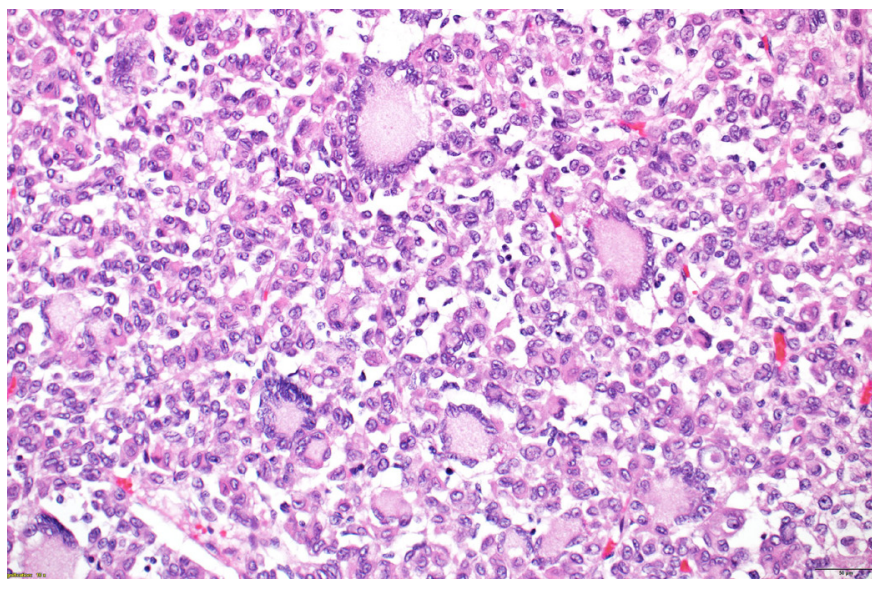

Fig. 3. Microscopy showing an oncocytic epithelioid tumour with large cells containing abundant eosinophilic cytoplasm with moderately pleomorphic nuclei and prominent nucleoli. There are scattered rhabdoid-like and ganglion-like cells with numerous multinucleated giant cells but limited mitotic figures. There were no areas of conventional angiomyolipoma.

Radiologically, angiomyolipoma and EAML have distinct differences however EAML can closely resemble RCC on imaging studies. Classical angiomyolipoma appear as heterogeneous, well-circumscribed masses with a signal density corresponding to its high fat component. EAML generally have a high cellular content and shows a lack of fat with variable enhancement on CT. Pathological bleeding, hyalinization and necrosis generate het- 
erogeneity, making EAML difficult to distinguish from RCC. MRI studies of EAMLs show an absence of fat and a high cellular content that makes it easy to confuse with $\operatorname{RCC}[8,9]$.

The main point to highlight is that EAMLs have a poor clinical outcome compared to classical, consistently benign angiomyolipoma. In a meta-analysis of 66 previous case reports, 30-50\% of EAMLs have shown malignant potential with local recurrence and lung metastasis [7]. Furthermore, Nese et al. [10] presented a case series of
41 patients whereby a third of patients eventually died from metastatic EAML.

Treatment consists of prompt surgical resection given the similarity in radiological appearance with RCC there is no evidence to support adjuvant chemotherapy or radiotherapy [9]. These patients need rigorous follow up, one suggested regimen being the European Association of Urology guidelines for "indeterminate risk cancers": CT scan at 6 months, then alternating CT scan/ ultrasound and chest X-ray yearly for 5 years.

\section{References}

1 Varma S, Gupta S, Talwar J, Forte F, Dhar M: Renal epithelioid angiomyolipoma: a malignant disease. J Nephrol 2011;24:18-22.

$>2$ Lai HY, Chen CK, Lee YH, Tsai PP, Chen JH, Shen WC: Multicentric aggressive angiomyolipomas: a rare form of PEComas. AJR Am J Roentgenol 2006;186:837-840.

>3 Martignoni G, Pea M, Rigaud G, Manfrin E, Colato C, Zamboni G, Scarpa A, Tardanico R, Roncalli M, Bonetti F: Renal angiomyolipoma with epithelioid sarcomatous transformation and metastases: demonstration of the same genetic defects in the primary and metastatic lesions. Am J Surg Pathol 2000:24: 889-894.
Kawaguchi K, Oda Y, Nakanishi K, Saito T, Tamiya S, Nakahara K, Matsuoka $\mathrm{H}$, Tsuneyoshi M: Malignant transformation of renal angiomyolipoma: a case report. Am J Surg Pathol 2002;26:523-529.

$>5$ Brimo F, Robinson B, Guo C, Zhou M, Latour M, Epstein J: Renal epithelioid angiomyolipoma with atypia: a series of 40 cases with emphasis on clinicopathologic prognostic indicators of malignancy. Am J Surg Pathol 2010;34:715-722.

$>6$ Eble JN: Angiomyolipoma of kidney. Semin Diagn Pathol 1998;15:21-40.

7 Faraji H, Nguyen BN, Mai KT: Renal epithelioid angiomyolipoma: a study of six cases and a meta-analytic study. Development of criteria for screening the entity with prognostic significance. Histopathology 2009;55: 525-534.
Bharwani N, Christmas TJ, Jameson C, Moat N, Sohaib SA: Epithelioid angiomyolipoma: imaging appearances. Br J Radiol 2009;82: e249-252.

$>9$ Hassan M, El-Hefnawy AS, Elshal AM, Mosbah A, El-Baz M, Shaaban A: Renal epithelioid angiomyolipoma: a rare variant with unusual behaviour. Int Urol Nephrol 2014;46: 317-322.

10 Nese N, Martignoni G, Fletcher C, Gupta R, Pan C, Kim H, Ro JY, Hwang IS, Sato K, Bonetti F, Pea M, Amin MB, Hes O, Svec A, Kida M, Vankalakunti M, Berel D, Rogatko A, Gown AM, Amin MB: Pure epithelioid PEComas (so-called epithelioid angiomyolipoma) of the kidney: a clinicopathologic study of 41 cases: detailed assessment of morphology and risk stratification. Am J Surg Path 2011;35:161-176. 